\title{
CONSTRUAL-MODERATED AUTOMATIC ASSOCIATIONS BETWEEN TEMPTATIONS AND GOALS
}

\author{
THESIS \\ Presented in Partial Fulfillment of the Requirements for \\ the Degree Master of Arts in the Graduate School of \\ The Ohio State University
}

By

Jo A. Sasota

$* * * * *$

The Ohio State University

2008

Thesis Committee:

Professor Kentaro Fujita, Advisor

Approved by

Professor William Cunningham

Professor Russ Fazio

Advisor

Graduate Program in Psychology 



\begin{abstract}
Past research indicates that high-level mental construals promote greater selfcontrol than low-level mental construals. High-level construals are thought to promote self-control because high-level construals preferentially weight global concerns over local concerns. The present work examines the precise social-cognitive mechanism by which the weighting of global over local concerns occurs. It was hypothesized that highlevel construals weight global concerns ahead of local concerns by keeping global concerns cognitively accessible. Four experiments support this logic. Specifically, it was found that the automatic activation of goals (global concerns) by temptations (objects associated with local concerns) occurred at high levels of construal but not at low levels of construal (Study 1 and 2). Furthermore, the inhibition of temptations by goals occurred at high levels but not low levels of construal (Study 3 and 4). These findings extend past work by illuminating the underlying social-cognitive mechanisms by which high-level construals promote self-control.
\end{abstract}


Dedicated to Ing and Shoots 


\section{ACKNOWLEDGMENTS}

I wish to thank my advisor, Kentaro Fujita, for the intellectual support, guidance, and unflagging enthusiasm which were essential for the completion of this thesis.

I would also like to thank the SCRG faculty, particularly Marilynn Brewer, William Cunningham, and Russ Fazio. The opportunity to learn from and engage in dialogue with world-renowned researchers is why I chose to study at OSU, and what has

made it a special, amazing experience. Thanks also to Margaret Shih who, as a faculty at Michigan, introduced me to world of social psychology.

I would also like to thank all of the graduate students, too numerous to list, who form my extended family at OSU. Special thanks to the graduate students in the Fujita Lab, particularly Joe Roberts, Karen MacGregor, and Reylissa Miranti; and the Cunningham lab, particularly Jay Van Bavel, Ingrid Johnsen, and Samantha Mowrer.

A special "thank you" also goes to all of my research assistants who helped make these studies possible: Elizabeth Kohlberg, Rachel Fisher, Doug Pritchett, Caroline Gault, and Kanwaldeep Kaur.

And, finally, thanks to my father, the late Jose Sasota, my mother, Cynthia Sasota-Wright, and my step-father, Carleton Wright for believing in me.

This research was supported by a grant from the Department of Homeland Security. 
VITA

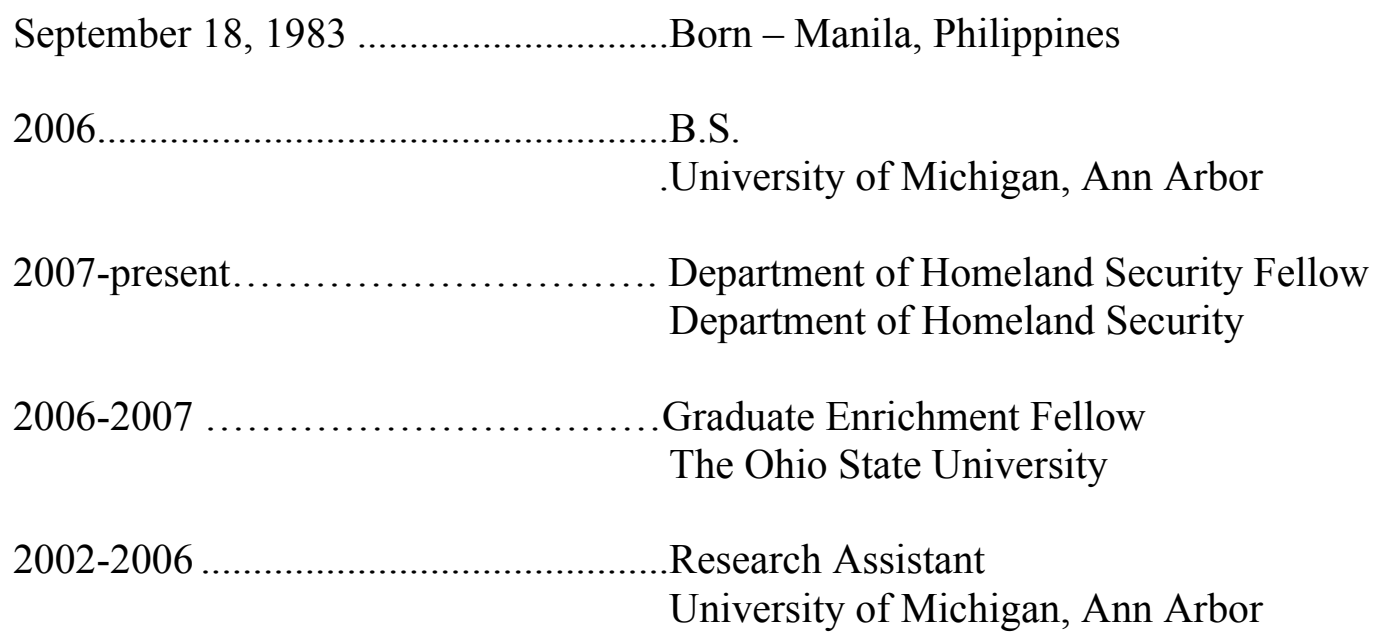

\section{FIELDS OF STUDY}

Major Field: Psychology 


\section{TABLE OF CONTENTS}

Page

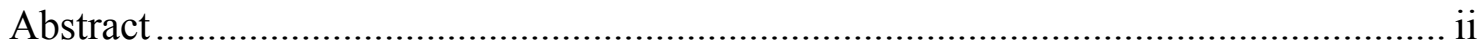

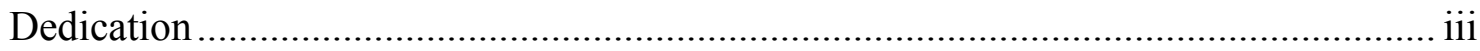

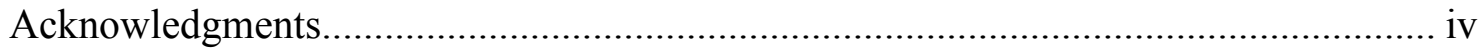

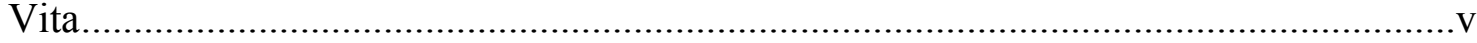

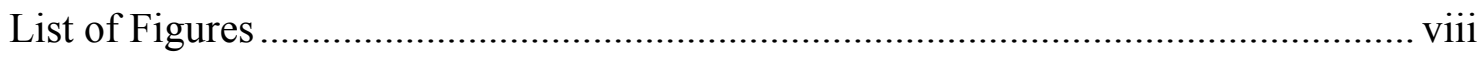

\section{Chapters:}

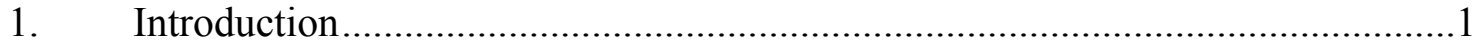

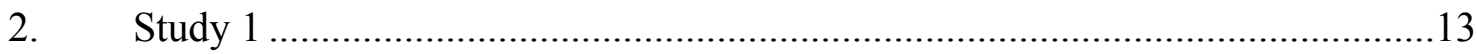

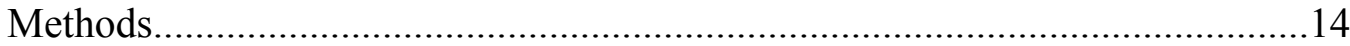

Results and Discussion ................................................................................

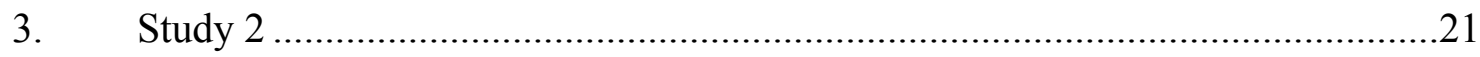

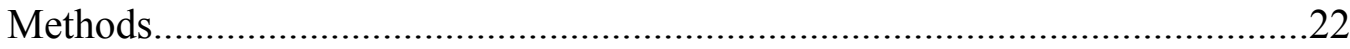

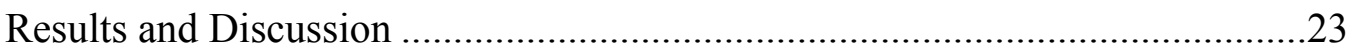

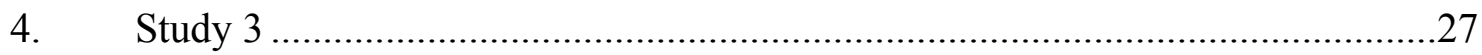

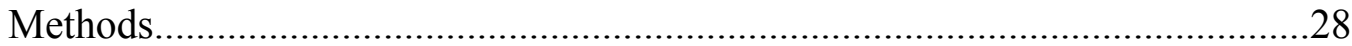

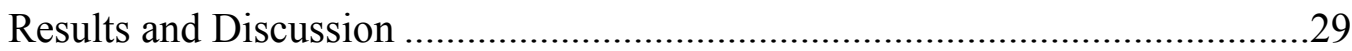

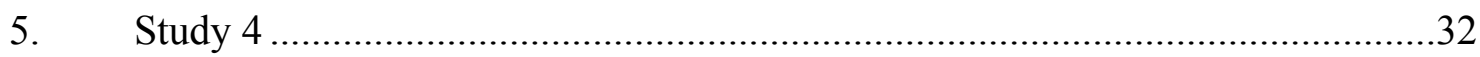

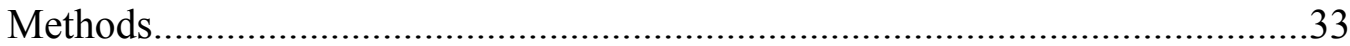

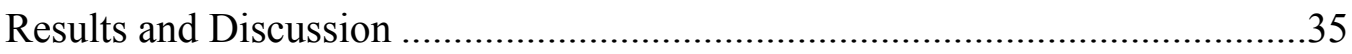

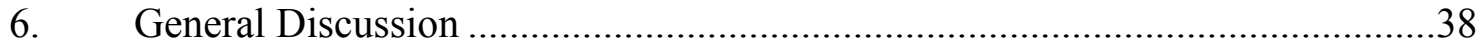

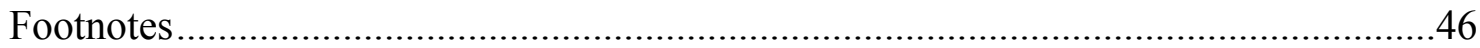

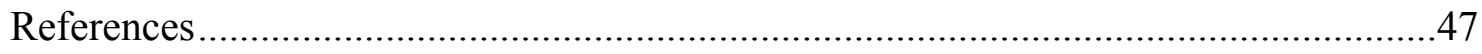

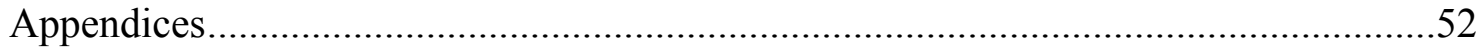


A: Stimuli. 


\section{LIST OF FIGURES}

$\begin{array}{lll}\text { Figure } & \text { Page }\end{array}$

1. The facilitation of goal-relevant objects by temptations as a function of construal

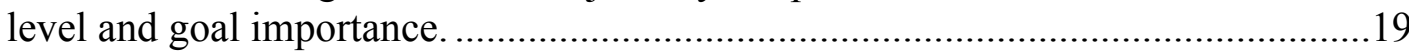

2. The facilitation of goal-relevant objects by temptations as a function of construal level and goal importance (replication) ……………….........................................24

3. The inhibition of temptations by goal-relevant objects as a function of construal level and goal importance.

4. The inhibition of temptations by goals as a function of construal level and goal

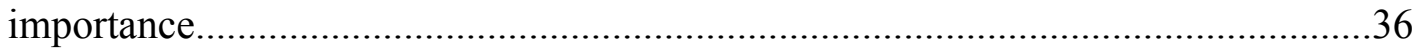




\section{CHAPTER 1}

\section{INTRODUCTION}

Failures of self-control represent one of the most widely recognized causes of individual and collective human suffering (Baumeister, Schmeichel, \& Vohs, 2007). Descriptions of such failures are ubiquitous in the media, and are exemplified in diverse areas such as substance abuse, obesity, criminal behavior, unsafe sex, and fiscal irresponsibility. Thus, understanding self-control, namely, the ability to do what one wants when possessing the knowledge, skills, and opportunities to do, so represents an important area of study. In fact, understanding what self-control entails and how selfcontrol may be promoted has been the focus of a multi-disciplinary research effort among researchers within psychology, behavioral economics, and neuroscience (Baumeister \& Heatherton, 1996; Metcalfe \& Mischel, 1999; Fujita, Trope Liberman, \& Levin-Sagi, 2006; Ainslie \& Haslam, 1992; Loewenstein, 1996; Gross, 2007). Self-control can be broadly conceptualized as making decisions and acting in accordance with global, rather than local concerns when given the opportunity to satisfy one or the other (Ainslie, 1975; Fujita et al., 2006). For example, for a dieter, being a handed the dessert menu at a restaurant may create a conflict between being healthy (a global concern) and having cheesecake (a local concern). Forgoing dessert would be an instantiation of self-control. 
However, conceptualizations of the processes involved in self-control and the factors that undermine and promote it are surprisingly varied (Baumeister \& Heatherton, 1996; Ainslie \& Haslam; Metcalfe \& Mischel, 1999; Fujita, Trope, Liberman, LevinSagi, 2006). One influential model describes self-control as the conscious control of undesired, automatic responses (Baumeister \& Heatherton, 1996). The automatic versus control model posits that when an undesirable, automatic response becomes elicited, consciousness control is required to override the response. Those who override undesirable, automatic responses by exerting conscious control are thought to be exercising self-control. Thus, in this model, global concerns are attained through the inhibition of automatic responses by conscious control. For example, for egalitarian individuals, negative stereotypes may become automatically activated when encountering a member of a stigmatized group (e.g., Devine, 1989). This automatically activated stereotype may in turn evoke unintended behavioral responses (e.g., Bargh, Chen, \& Burrows, 1996). Importantly, however, given sufficient conscious resources, the influence of automatically activated stereotypes can be controlled. In line with this thinking, Macrae, Hewstone, and Griffiths (1993) found that participants applied more stereotype-consistent information to their judgments when under cognitive load than when they were not. In this model of self-control, self-control failures increase when the availability of conscious resources decreases. Accordingly, factors that undermine selfcontrol are factors that impinge on conscious resources.

A "strength" account of self-control is an extension on the automatic versus control model of self-control. A strength account of self-control proposes that exerting conscious control to regulate undesirable, automatic impulses requires expending energy 
from a limited self-regulatory "muscle" (e.g., Muraven \& Baumeister, 2000; Baumeister et al., 2007). Once the energy is depleted subsequent attempts at self-control are likely to result in failure. For example, for a dieter, forgoing dessert at dinner is less likely if one had to forgo tempting food throughout the day (e.g., forgoing bacon and eggs at breakfast, the donut at work, the hamburger at lunch and so on). As in the case with other muscles, we can exercise the self-control muscle - resulting in improved selfcontrol (Baumeister, Gailliot, DeWall, Oaten, 2006). Thus, to improve self-control and attain our global concerns, individuals are advised to strengthen their self-control muscle and to avoid situations where self-control is needed (Aamodt \& Wang, 2008).

Another popular school of thought describes self-control as making decisions and taking actions that are in accordance with larger, long-term outcomes rather than smaller, short-term outcomes (Ainslie \& Haslam, 1992; Thaler, 1991; Trope \& Fishbach, 2000). Self-control failures occur when individuals favor the smaller, short-term outcome rather than the larger, long-term outcome. In the long-term versus short-term model of selfcontrol, self-control failures are posited to occur because individuals value future rewards in a hyperbolic fashion. That is, outcome values increase disproportionately when the outcomes are near in time than when the outcomes are distant in time. As a result of the hyperbolic value functions, the time at which outcomes are attained drastically affects behavior and leaves individuals prone to preference reversals and time-inconsistent preferences. For example, research has demonstrated that the vast majority of people prefer to receive $\$ 20$ now versus $\$ 50$ a year from now. However, the addition of a constant delay to both choice options leads them to reverse their preferences (i.e., choosing $\$ 50$ three years from now over $\$ 20$ two years from now; e.g., Green, Fristoe, \& 
Myerson, 1994). Accordingly, the long-term versus short-term model of self-control suggests that people are more likely to attain their global, rather than local, concerns when the outcomes are distant rather than near in time. Consistent with this logic is research looking at the factors that promote saving for retirement. Saving for retirement involves self-control because people want to spend the money they have now instead of save the money for later. This research showed that employees are more willing to, and do, put money into a retirement account if the decision to do so is made far in advance rather than nearer in time (Benartzi \& Thaler, 2004).

Another well-accepted conceptualization of self-control frames self-control in terms of actions initiated by two different cognitive systems, a "hot system" or a "cool system” (Metcalfe \& Mischel, 1999; Mischel, Shoda, \& Rodriguez, 1989). The hot system consists of affective mental representations or "hot" cognitions, and when activated lead to impulsive behavioral responses. In contrast, the cool system consists of emotionally neutral, "cool" cognitions, and when activated lead to deliberate, reflective behavior. From this perspective, self-control involves the preferential activation of the cool system over the hot system. In other words, global concerns are attained by preferentially activating the cool, rather than hot, system. For example, children have been shown to postpone the consumption of a tasty marshmallow if they think of the marshmallow in cool manner ("It is white and puffy like a cloud") than if they think of the marshmallow in a hot manner ("It looks tasty," Mischel \& Baker, 1975). Accordingly, self-control is likely to fail when the hot system is activated over the cool system. Factors that promote the activation of the hot system over the cool system, like focusing on the appetitive features of an object, will undermine self-control whereas 
factors that promote the activation of the cool system over the hot system, for example, metacognitive strategies that mentally transform temptations into nonappetitive objects, will enhance self-control.

In an attempt at theoretical coherence regarding what self-control entails and how it may be promoted, it has been suggested that self-control success and failure be explained by the level of abstraction in which self-control conflicts are mentally represented and the actions associated with these representations (Fujita et al., 2006). Specifically, Fujita et al. (2006) argue that the level of abstraction in which self-control conflicts are mentally represented directly influences the weighting of global versus local concerns and thus influences self-control. According to this model of self-control, selfcontrol is enhanced when the proverbial forest can be seen through the trees but is impaired when one loses sight of the forest. This model of self-control is based on Construal Level Theory (CLT).

\section{Construal Level Theory}

CLT posits that the same object or event can be mentally represented at multiple levels of abstraction (Trope \& Liberman, 2003). High-level construals are mental representations that extract the gist of objects and events. That is, high-level construals capture central, defining features of objects and events. Thus, high-level construals capture features that are common among all instances of a given class of objects or events. For example, a student might think of the event "studying" as an opportunity to master some material or as a chance to clarify difficult information; these features can be thought of as the defining, high-level features of the class of events "studying." Conversely, low-level construals are mental representations that capture unique, 
incidental features of objects and events. For instance, where the student is studying or what color highlighter he is using are unique, incidental features that are irrelevant to studying.

Research has shown that high-level and low-level construals are distinct. For example, the activation of high-level construals has been show to lead to more abstract categorization which results in fewer but broader units of categorization, whereas the activation of low-level construals has been shown to lead to more concrete categorization which results in multiple, narrow units of categorization (Liberman, Sagristano, \& Trope, 2002, Study 1). In addition to categorization, preferences and behaviors are also influenced by level of construal. When, high-levels of construal are activated, more weight is given to high-level features in preferences and actions. On the other hand, when low-levels of construal are activated, more weight is given to low-level features (Trope \& Liberman, 2000). For example, individuals who want to purchase a new radio have to consider many features before deciding what particular radio to purchase. They have to consider the central, high-level features of radios, such as the quality of the radio reception in addition to more peripheral, low-level features, such as aesthetic appeal of the clock display. Research has shown that the activation of high-level construals when making consumer decisions, such as buying a radio, leads to greater preference for items that possess high quality high-level features, but poor quality low-level features (i.e., radios that possesses nice radio reception but poor clocks) but the activation of low-level construals leads to greater preference for items that possess poor quality high-level features, but high quality low-level features (i.e., radios with poor radio reception but nice clocks; see Trope \& Liberman, 2000, Study 3). 
Levels of construal can be activated in multiple ways. An important factor that determines what level of construal is activated is psychological distance. Distancing the target object or event on any psychological dimension (time, geographic space, social distance, hypotheticality, probability) preferentially activates high-, rather than low-, levels of construals (Liberman, Trope \& Stephan, 2007). Levels of construal can also be procedurally primed (Smith \& Branscombe, 1987) by the construals used in prior, unrelated settings. For example, imagining future events has been show to promote abstract thinking, whereas imagining near future events has been shown to promote concrete thinking (Forster, Friedman, \& Liberman, 2004). The cognitive procedures associated with each level of construal can also activate high- or low-level construals (Freitas, Gollwitzer, \& Trope, 2004). For example, high- and low-level construals can be activated by asking participants why versus how engage in particular actions, respectively (Freitas et al., 2004).

\section{A Construal Level Approach to Self-control}

A construal level approach posits that self-control conflicts emerge when the action tendencies associated with the high-level construal are in direct opposition to the action tendencies associated with the low-level construal (Fujita et al., 2006). For example, as mentioned earlier, for a person committed to dieting, being a handed the dessert menu at a restaurant may create a conflict between "eating cheesecake" (a local, low-level concern that suggests eating the cheesecake) vs. "being healthy" (a global, high-level concern that suggests forgoing the dessert). Making a decision to forgo dessert would entail putting global concerns ahead of local concerns and making a decision on the basis of high-level over low-level construals. 
Because high levels of construal cause high-level features (e.g., global concerns) to be preferentially weighted over low-level features (e.g., local concerns; Trope \& Liberman, 2000; Fujita et al., 2006) the activation of high-levels of construal should promote self-control. Hence, a construal level approach to self-control makes a very clear prediction. Namely, that activating high levels of construal should lead to greater self-control than low levels of construal during a self-control conflict (Fujita et al., 2006). The empirical evidence supporting this line of thought is impressive in that the hypothesis is supported across a variety of self-control conflicts. For example, highlevel, rather than low-level construals, led to decreased preferences for immediate over delayed outcomes in situations where the immediate outcome is usually preferred (Fujita et al., 2006, Study 1). The activation of high-level, rather than low-level construals, also led to greater physical endurance in an unpleasant, physically challenging task to obtain self-relevant feedback (Fujita et al., 2006, Study 2). High-level construals also led to less positive evaluations of temptations that undermine goals (Fujita et al., 2006, Study 4 and 5). Across a variety of self-control domains, the activation of high-, rather than low-, level construals was shown to promote self-control (Fujita et al., 2006). However, the precise social cognitive mechanism by which high-, rather than low-, level construals promote the weighting of global concerns over local concerns and thus self-control has yet to be established.

From a cognition as motivation perspective (e.g., Kruglanski, Shah, Fishbach, Friedman, Chun, Sleeth-Keppler, 2002), one way that high-level construals may preferentially weight global concerns ahead of local concerns is by keeping global concerns cognitively accessible. Two mechanisms must be in place to ensure this 
(Fishbach, Friedman, \& Kruglanski, 2003). First, temptations (i.e., objects associated with local concerns) must automatically activate thoughts of goals (i.e., global concerns). In this way, even though temptations are encountered, goals can still color evaluation and decision-making in favor of self-control. A second way to keep our global concerns accessible is that when thinking of them, local concerns do not come to mind. If local concerns are not brought to mind, they cannot affect decision-making or behavior. Thus, one mechanism whereby high-level construals promote the weighting of global concerns over local concerns, and thus self-control, is by keeping global concerns accessible.

Consistent with this logic, Fishbach et al. (2003) discovered asymmetric activation patterns between temptations and goals. Specifically, Fishbach et al. (2003) found that temptations automatically activated thoughts about goals but thoughts about goals inhibited thoughts about temptations. (See Footnote 1). In other words, Fishbach et al. (2003) discovered that when encountering objects that may satisfy local concerns (i.e., temptations) thoughts of global concerns (i.e., goals) automatically come to mind. On the other hand, when thinking of global concerns thoughts of local concerns become less accessible. This pattern of activation between temptations and goals is consistent with the aforementioned model of how high-level construals may weight global concerns ahead of local concerns.

Importantly, the asymmetric activation pattern between temptations and goals has been shown to influence self-control behaviors in a variety of domains (Fishbach et al., 2003). For example, for college students, in the battle between procrastinating and studying, the more students exhibited these asymmetric activation patterns the more they reported being successful in completing their academic coursework (Fishbach et al., 
2003, Study 3). That is, after being primed with a temptation-related word like internet (class), the faster (slower) the students were able to identify a goal-related word (temptation-related word) like graduate (television) the more self-control they reported. Illustrating the causal impact of these asymmetric activation patterns, Fishbach et al. (2003, Study 5) found that dieters who were environmentally primed with temptations, were more likely to choose an apple, over a candy bar at the end of the experiment than dieters who were not environmentally primed with temptations. Across a variety of selfcontrol domains, the asymmetric cognitive activation between temptations and goals has been shown to promote self-control.

Thus, high-level construals may promote self-control by promoting the use of these asymmetric activation patterns. Under this conceptualization, the automatic cognitive activation of goals (i.e., global concerns) by temptations (i.e., objects associated with local concerns) and the inhibition of temptations by goals are mechanisms by which high-level construals weight global concerns ahead of local concerns. The present research examines whether the asymmetric activation pattern between temptations and goals is more likely observed at high-, rather than low-, levels of construal. If construal levels moderate the associations between temptations and goals, then it would suggest that these associations are mechanisms by which high-level construals promote selfcontrol.

\section{The Present Studies}

We conducted four experiments to test the hypothesis that the activation of high levels of construal would lead to greater asymmetric activations between temptation and goals than low levels of construal. In all four experiments, we experimentally induced 
high or low levels of construal by procedural priming. Specifically, the participants used high- or low-level construals in a separate, unrelated task (Smith \& Branscombe, 1987; Freitas, Gollwitzer, \& Trope, 2004). We then observed the carryover effects that these primed construal levels had on a lexical decision task that was designed to assess the cognitive association between temptations and goals.

In the first two experiments we examined the cognitive activation of goal-relevant objects by temptations. In the third experiment we examined the cognitive activation of temptations by goal-relevant objects. In the fourth and last experiment, we examined the cognitive activation of temptations by goals. While goal-relevant objects have been used as proxies for goals (Fishbach et al., 2003), they are conceptually distinct from goals. Goal-relevant objects are objects that promote the attainment of a goal and are only relevant to the extent that one possesses the goal. For example, for dieters, objects that promote being thin like carrots, celery, and broccoli are all relevant in light of wanting to be thin and thus can be considered goal-relevant objects. On the other hand, goals are desired end-states (Fishbach \& Ferguson, 2007) that are attained through particular means. In our example, for dieters, dieting may serve as a means to attain the goal of being thin. Previous research has used goal-relevant objects (Fishbach et al., 2003, Study 2 and 3) in addition to goals (Fishbach et al., 2003, Study 4) to examine the asymmetric activation patterns between temptations and goals. Study 4 was designed to show that construal levels would affect the cognitive accessibility of temptations using the goals themselves in addition to their proxies (i.e., goal-relevant objects).

We predicted that activation of high-level construals would result in greater activation of goal-relevant objects by temptations (Study 1 and Study 2) and greater 
inhibition of temptations by goal-relevant objects and goals (Study 3 and Study 4, respectively). However, since these asymmetric activations serve as mechanisms of selfcontrol, then it should be evident only among those who actually experience a selfcontrol conflict. That is, the effect of construal levels on the activation of goal-relevant objects by temptations (Study 1 and 2) and inhibition of temptations by goal-relevant objects and goals (Study 3 and Study 4) should be specific to those who experience a self-control conflict. As such, participants were asked to report how important the goal was to them. Presumably, participants concerned with the goal will experience a selfcontrol conflict when encountering temptations that may undermine the goal whereas those unconcerned with the goal are unlikely to experience a self-control conflict when encountering temptations that may undermine the goal. We predicted that among those for whom the goal was important, high-level construals would promote the activation of goal-relevant objects by temptations and the inhibition of temptations by goal-relevant objects and goals. However, we predicted that among those for whom the goal was not important, there would be little or no effect of construal level. 


\section{CHAPTER 2}

\section{STUDY 1}

Participants completed an exercise designed to procedurally prime high- or lowlevel construals. Half of the participants were procedurally primed to construe at highlevels by generating answers as to why they perform certain activities (abstracting the superordinate concerns motivating the behavior) whereas the other half of participants were procedurally primed to construe at low-levels by generating answers as to how they perform certain activities (specifying the means by which they implement the behavior). Previous research has demonstrated that considering questions of why are effective in procedurally priming high-level construals, whereas considering questions of how are effective in procedurally priming low-level construals (Freitas et al., 2004; Fujita et al., 2006).

After the construal-level manipulation, the automatic activation of goal-relevant objects by temptations was assessed using a lexical decision-based sequential priming procedure modeled after Fishbach et al. (2003). Using dieting as the focal self-control conflict, we measured the activation of dieting-related object words by temptation versus non-temptation words. We predicted that high-level construals would promote the activation of dieting-related object words by temptation primes. However, since the 
activation of goal-relevant objects by temptations serves as a mechanism of self-control, it should be evident only among those who actually experience a self-control conflict (Fishbach et al., 2003). That is, the effect of construal level on the activation of goalrelevant objects by temptations should be specific to those for whom dieting is a meaningful self-control conflict. As such, participants were asked to report to what extent dieting was an important goal to them. We predicted that those for whom dieting was an important goal (i.e., those likely to experience a self-control conflict), high-level construals would promote the activation of goal-relevant objects by temptations.

However, we predicted that those for whom dieting was not an important goal (i.e., those unlikely to experience a self-control conflict), there would be little or no effect of construal level.

\section{Method}

\section{Participants}

Participants were 93 Ohio State University undergraduate students (38 women), who completed the study in exchange for course credit. Participants were randomly assigned to condition and tested in groups of 1 to 4 .

Materials \& Procedure

Construal-level manipulation. Participants first completed an exercise designed to procedurally prime high- or low-level construals. The construal-priming manipulation was modeled after Freitas et al. (2004). Half of the participants were procedurally primed by considering why they engaged in certain actions. Specifically, high-level participants were presented with the questions "Why do I go to bed on time?" and "Why do I call my parent(s) on the phone?" They were then given a diagram of vertically aligned boxes that 
began at the bottom of the page and were connected by upward arrows labeled Why? (see Freitas et al., 2004). The box at the very bottom of the diagram was filled with the statement "Go to bed on time" or "Call parent(s) on phone." Participants were first presented the diagram with the question "Why do I go to bed on time?" Upon completion, participants were then asked to complete the diagram with the question "Why do I call my parent(s) on the phone?"

The other half of participants were procedurally primed at low-levels by considering how they engaged in certain actions. Specifically, low-level participants were presented with the questions "How can I attain life happiness?" and "How can I improve and maintain good grades?" They were then given a diagram of vertically aligned boxes that began at the top of the page and were connected by downward arrows labeled How? (see Freitas et al., 2004). The box at the very top of the diagram was filled with the statement "Attain life happiness" or "Improve and maintain grades." Participants were first presented the diagram with the question "How can I attain life happiness?" Upon completion, participants were then asked to complete the diagram with the question "How can I improve and maintain good grades?"

In each diagram, participants were instructed to insert a response in the box immediately above the bottom box (below the top box), answering the question of why they would go to bed on time (how they could attain life happiness) or why they would call their parent(s) on the phone (how they could improve and maintain good grades). After inserting their first answer, they were to insert a second response in the box immediately above (below) the box they had just completed answering the question why (how) they would engage in their initial response. For example, a participant could have 
answered the question, "Why do I go to bed on time?" ("How can I attain life happiness") by writing, "To get to class" ("Having money"). The diagram would then prompt the participant to ask "Why do I want to get to class?" ("How do I obtain money?"). Upon completing that answer, the participant would then be prompted again by the diagram to consider why they would engage in the response provided. Participants provided four responses in this manner for both diagrams.

Lexical decision task. After the participants completed the construal-level exercise, they completed a lexical decision-based sequential priming task (LDT) on a computer. The LDT was designed to measure the automatic activation of goal-relevant objects by temptations. Participants were presented with a series of letter strings and were asked to determine as quickly as possible whether the letter string was a word or nonword. At the beginning of each trial, a turquoise (all stimuli were presented in a turquoise font) fixation point $(a+$ sign $)$ appeared on the middle of a black screen for 1000 ms. Participants were instructed to focus their attention on the fixation point. The fixation point was then replaced with a prime word for $300 \mathrm{~ms}$. After the prime word was removed, a blank black screen was presented for $50 \mathrm{~ms}$. A target letter string was then presented, resulting in a stimulus onset asynchrony (SOA) of $350 \mathrm{~ms}$. Previous research has demonstrated that SOAs of $350 \mathrm{~ms}$ or less reflect automatic associations between primes and target judgments (Neely, 1977; Blair \& Banaji, 1996). The letter string remained until the participant indicated whether the letter string was a word or not.

Participants decided whether the target letter string was a word or nonword using the right-ctrl and left-ctrl keys, respectively. Each response was followed by a 1-sec delay. A total of 80 trials were presented, half of which represented word trials (40 
trials). Of these latter trials, 20 trials presented target words that were foods related to dieting. In 10 of these trials (critical trials), the goal-relevant objects (e.g., broccoli, carrot, tofu) were preceded by temptation primes that could undermine dieting goals (e.g., fries, beer, nachos). In an additional 10 of these trials (comparison-trials), the goalrelevant objects were preceded by irrelevant, neutral primes (e.g., door, square, horse). The specific prime-target pairings were determined through random selection by the LDT program. The remaining 20 trials were neutral trials and consisted of identifying neutral target words as words or nonwords after being exposed to neutral primes.

The goal-relevant object and temptation word stimuli were selected and validated through pretesting (see Appendix A for the full list). Sixty-nine Ohio State University undergraduates (43 women) participated in the pre-testing of stimuli for partial course credit. In groups of 10-15, participants were given a packet to complete. In the packet, participants were asked how much they associated a given word with undermining versus promoting the goal to diet. Specifically, participants were given a word (e.g., bacon) and asked how much they associated the word with undermining the goal to $\operatorname{diet}(1=$ not at all, $6=$ extremely) and how much they associated the word with promoting the goal to $\operatorname{diet}(1=$ not at all, 6 = extremely) using a 6-point Likert scale. For each word, a difference score was calculated by subtracting the average "promoting" score from the average "undermining" score. The twenty food words with the most positive difference scores were chosen as the goal words. The twenty food words with the most negative difference scores were chosen as the temptations.

Measurement of goal importance. After the participants completed the LDT they were asked four questions designed to assess how important it was for them to diet. The 
four items were "To what extent do you avoid high-fat, high-calorie foods?," "How concerned are you about eating healthy foods?," "To what extent do you make an effort to eat low-fat, low-calorie foods?," and "How guilty would you feel if you consistently ate high-fat, high-calorie foods?" Participants responded using a 7-point Likert scale $(1=$ not at all, $7=$ extremely). The four items were averaged to obtain an index of goal importance $(\alpha=.84)$. Participants then provided demographic information (e.g., gender, age, year in school). Upon completion, a funneled debriefing was administered. None of the participants reported a relationship between the construal-level manipulation exercise and the LDT. Afterward, they were carefully debriefed and dismissed.

\section{Results and Discussion}

The activation of goal-relevant objects by temptations was measured using a facilitation score. Given the difficulty of interpreting latencies for errors, only correct responses were used in all of the following analyses (see Bargh, Chaiken, Govender, \& Pratto, 1992; Fazio, 1990). The average error rate for participants in the LDT was $8.7 \%$. To control for excessive positive skew, response latencies were trimmed within $\pm 2.5 S D$ of each participants' cell mean. The facilitation score was then calculated by subtracting the average response latencies in the critical trials (temptations priming goal-relevant objects) and the average response latencies in the comparison trials (neutral words priming goal-relevant objects). The more negative the facilitation score the more goalrelevant objects were accessible.

Facilitation scores were regressed onto construal level and goal importance. Replicating the work by Fishbach et al. (2003) a significant effect of goal importance emerged such that as the importance of dieting increased, the activation of goal-relevant 
objects by temptations increased, $B=-.19, t(89)=-1.65, p=.10$. More importantly, there was a significant interaction between construal level and goal importance, $B=-.30$, $t(89)=-2.65, p=.01($ see Figure 1$)$.

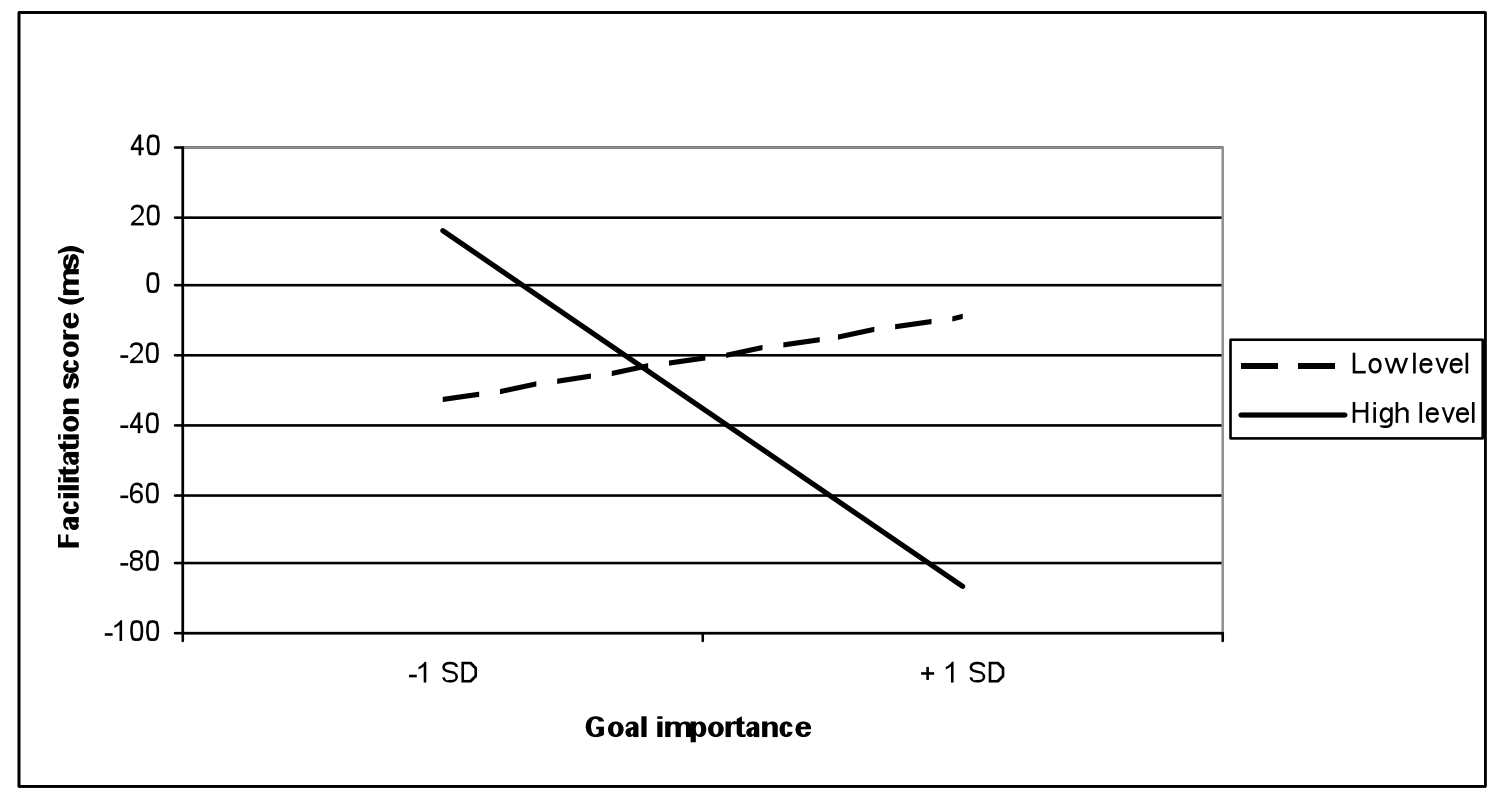

Figure 1. The facilitation of goal-relevant objects by temptations as a function of construal level and goal importance. The more negative the facilitation score the more goal-relevant objects became accessible. When the goal was important, defined as one standard deviation above the mean, high-level construals led to more activation of goalrelevant objects by temptations than low-level construals.

For those whom dieting was important and thus represented a meaningful selfcontrol conflict, high-, rather than low- construals facilitated the activation of goalrelevant objects by temptations, $B=-.37, t(89)=-2.46, p=.01$. On the other hand, for those whom dieting was not important and thus did not represent a meaningful selfcontrol conflict, construal levels did not significantly affect the activation of goal-relevant objects by temptations, $B=.23, t(89)=1.47, p=.15$. 
These analyses support two conclusions. First, high-, rather than low-, level construals promote the activation of goal-relevant objects by temptations. Second, highlevel construals promote the activation of goal-relevant objects by temptations only for those who experience a self-control conflict (i.e., those participants indicating that dieting was important). Taken together, the analyses support the conclusion that goal-relevant objects were automatically activated by temptations for participants who reported that dieting was of high importance and were at the high-level construal. We would like to suggest this data provides support for the idea that automatic activation of goals by temptations is one of the mechanisms by which high-level construals weight global concerns ahead of local concerns and thus promote self-control.

One potential issue of the present design is the construal level manipulation exercise implemented. Whereas, Freitas et al. (2004) had participants start from the same activity, health improvement, to create superordinate means or subordinate ends, we had participants start from different activities. Thus it is not clear whether it was the difference in the activities participants considered, or the differences in the manner in which participants considered them that produced the obtained effects. It is difficult to imagine how the specific activities participants considered during the exercise might have led to the specific pattern of data that was predicted and found. Nevertheless, Study 2 addresses this issue by procedurally priming high- or low-level construals with the same stimuli. In this way, Study 2 addresses an issue that could be raised in Study 1 in addition to replicating the results of Study 1 . 


\section{CHAPTER 3}

\section{STUDY 2}

Study 2 was designed to conceptually replicate the findings in Study 1. A different construal-level manipulation exercise was implemented in Study 2; however, all other procedures and analyses from Study 1 remained the same. As in Study 1, we predicted that the automatic activation of goal-relevant objects by temptations would be dependent upon construal level and goal importance. Specifically, we predicted that high-, rather than low-, level construals would promote the activation of dieting-related object words by temptations. However, since the activation of goal-relevant objects by temptations serves as a mechanism of self-control, it should be evident only among those who actually experience a self-control conflict. That is, the effect of construal level on the activation of goals by temptations should be specific to those for whom dieting is a meaningful self-control conflict. Presumably, participants concerned with the goal will experience a self-control conflict when encountering temptations that may undermine the goal whereas those unconcerned with the goal are unlikely to experience a self-control conflict when encountering temptations that may undermine the goal. Thus, we predicted that those for whom dieting was an important goal, high-level construals would promote the activation of goal-relevant objects by temptations. However, we predicted that those 
for whom dieting was not an important goal, there would be little or no effect of construal level.

\section{Method}

\section{Participants}

Participants were 126 Ohio State University undergraduate students (78 women), who completed the study in exchange for course credit. Participants were randomly assigned to condition and were tested in groups of 1 to 4 .

\section{Materials \& Procedure}

Construal-level manipulation. Participants first completed a construal-priming manipulation validated by Fujita et al. (2006). Participants were presented with 40 words such as actor, king, college and movie, individually on the computer monitor. Half of the participants were procedurally primed to construe at high-levels by generating superordinate category labels for the 40 words while the other half of participants were procedurally primed to construe low-levels by generating subordinate exemplars for the 40 words. Generating superordinate category labels induces a tendency to construe objects and events at high-levels of abstraction whereas generating subordinate exemplars induces a tendency to construe objects and events at low-levels of abstraction (Fujita et al., 2006)

Those in the high-level construal condition were instructed to generate superordinate category labels by answering the question, “__ is an example of what?" For example, when given college, participants in the high level condition could respond with "educational institution." On the other hand, those in the low-level construal condition were instructed to generate subordinate exemplars by answering the question, 
"An example of __ is what?" For example, when given college, participants in the low level condition could respond with "Ohio State."

Other measurements. All other materials and procedures were identical to those used in Study 1. As in Study 1, the responses to the goal importance questions were averaged to obtain an index of goal importance $(\alpha=.90)$. As in the previous study, none of the participants reported a relationship between the construal-level manipulation exercise and the LDT.

\section{Results and Discussion}

As in Study 1, the activation of goal-relevant objects by temptations was measured using a facilitation score. Again, only response latencies associated with correct trials were included in analysis (Bargh et al., 1992; Fazio, 1990). The average error rate for participants in the LDT was 9.0\%. First, to control for excessive positive skew, response latencies were trimmed within $\pm 2.5 S D$ of each participants' cell mean. The facilitation score was then calculated by subtracting the average response latencies in the critical trials (temptations priming goal-relevant objects) and the average response latencies in the comparison trials (neutral words priming goal-relevant objects). The more negative the facilitation score the more goal-relevant objects were accessible.

As in Study 1, facilitation scores were regressed onto construal level and goal importance. Although not statistically significant, the effect of goal importance replicated work by Fishbach et al. (2003) and the findings from Study 1, $B=-.11, t(122)$ $=-1.23, p=.21$. That is, as the importance of dieting increased, activation of goalrelevant objects by temptations increased. More importantly, as in Study 1, there was a 
significant interaction between construal level and goal importance, $B=-.27, t(122)=-$ $2.09, p=.04$ (see Figure 2).

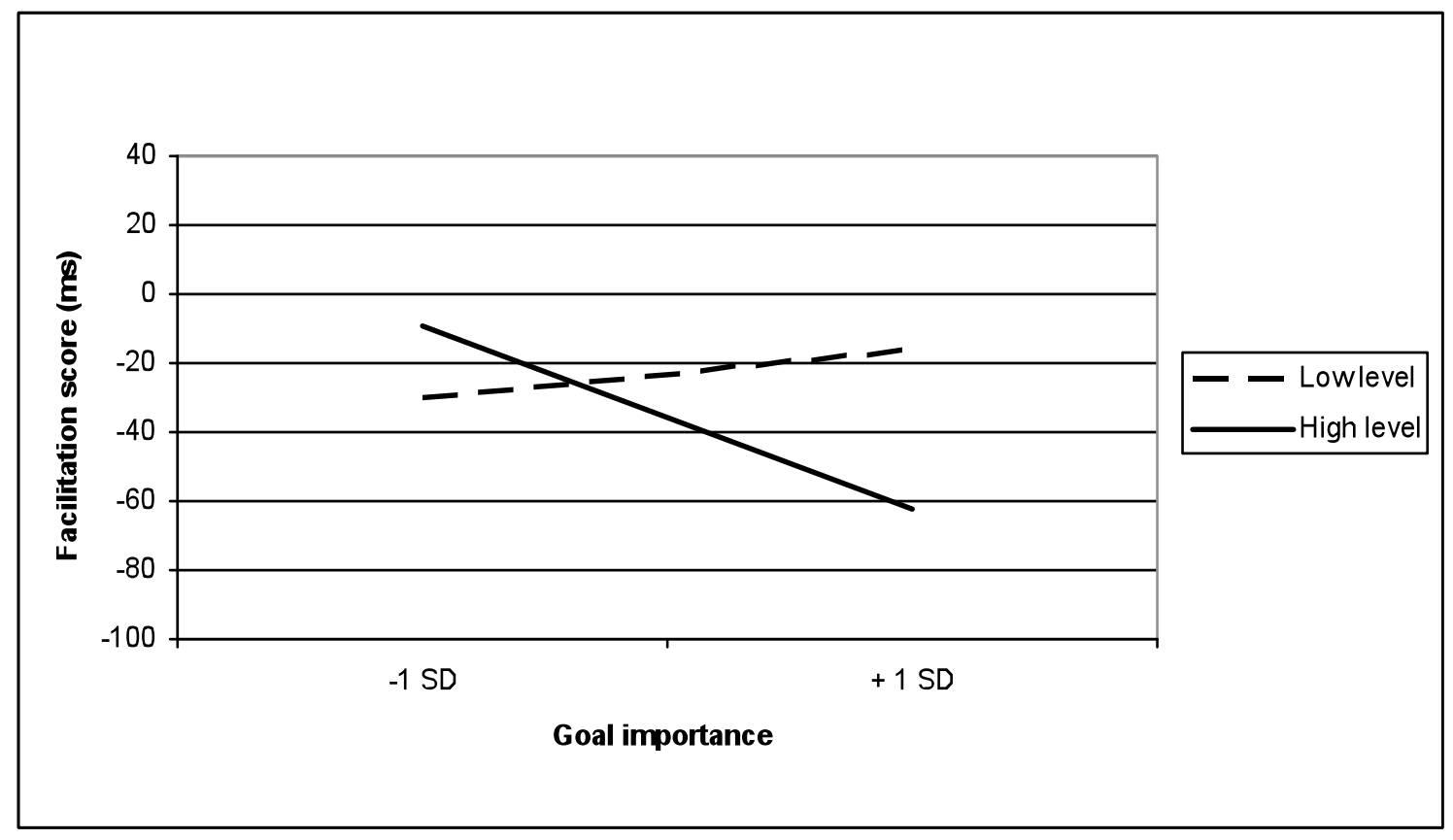

Figure 2. The facilitation of goal-relevant objects by temptations as a function of construal level and goal importance. The more negative the facilitation score the more goal-relevant objects became accessible. When the goal was important, defined as one standard deviation above the mean, high-level construals led to more activation of goalrelevant objects by temptations than low-level construals.

For those whom dieting was important and thus represented a meaningful selfcontrol conflict, high-, rather than low-level construals facilitated the activation of goalrelevant objects by temptations, $B=-.27, t(122)=-2.09, p=.04$. On the other hand, for those whom dieting was not important and thus did not represent a meaningful selfcontrol conflict, construal levels did not affect the activation of goal-relevant objects by temptations, $B=.12, t(122)=0.93, p=.36$. 
These analyses support the same conclusions made in Study 1. First, high-, rather than low-, level construals promote the activation of goal-relevant objects by temptations. Second, high-level construals promote the activation of goal-relevant objects by temptations only for those who experience a self-control conflict, across two studies, participants concerned with dieting. In sum, the two studies support the conclusion that goal-relevant objects were automatically activated by temptations for participants who reported that dieting was of high importance and were at the high-level construal. Again, we would like to suggest this data provides support for the idea that automatic activation of goals by temptations is one of the mechanisms by which high-level construals weight global concerns ahead of local concerns and thus promote self-control.

These two studies support the notion that high-, rather than low-, level construals promote self-control because the activation of goal-relevant objects by temptations only occurred for individuals who were at the high-level. We would suggest that the activation of goal-relevant objects by temptations is one of the mechanisms by which high-level construals promote the weighting of global concerns ahead of local concerns in selfcontrol conflicts. We suggest that when experiencing a self-control conflict, construing the conflict at an abstract, high-level may promote self-control because thoughts of our global concerns become activated when temptations (i.e., objects associated with local, secondary concerns) are encountered (Fishbach et al., 2003; Fujita et al., 2006). However, construing the conflict at a concrete, low-level may lead to self-control failure because thoughts of our global concerns do not become activated when encountering temptations. To put it more concretely using dieting as the self-control conflict, we suggest, that dieters at the high-level are more likely to think of their dieting goals and 
diet-relevant foods when encountering temptations, and as such, are more likely to exert self-control (Fishbach et al., 2003, Study 5). On the other hand, we suggest, dieters at the low-level are less likely to think of their dieting goals and diet-relevant foods when encountering temptations, and as such, may fail to exert self-control.

The findings from Study 1 and Study 2 demonstrated that the automatic activation of goal-relevant objects by temptations is moderated by construal level. However, exerting self-control not only requires thinking of goals when encountering temptations in a self-control conflict but also requires that when thinking of them, temptations do not come to mind (Fishbach et al., 2003). Since Study 1 and Study 2 showed that construal levels moderated the automatic cognitive activation of goals by temptations, Study 3 was designed to assess whether construal levels would moderate the inhibition of temptations by goals. Consistent with the theme that high-, rather than low-, level construals promote self-control (Fujita et al., 2006), we predicted the inhibition of temptations by goalrelevant objects at the high-, but not low-, level construal. 


\section{CHAPTER 4}

\section{STUDY 3}

Study 3 was designed to assess whether the inhibition of temptations by goalrelevant objects is moderated by construal levels. Participants completed the construallevel manipulation exercise used in Study 2 to procedurally prime high or low levels of construal. After the construal-level exercise, the carryover effects of the exercise were observed on a lexical decision task that was designed to assess the cognitive association between temptations and goals. However, instead of temptations priming goal-relevant objects, goal-relevant objects were used to prime temptations.

Using dieting as the focal self-control conflict, we measured the activation of temptation words by dieting-related object words versus non-dieting-related object words. We predicted the inhibition of temptations by goal-relevant objects would happen at the high-, rather than low-, level construal. However, since the inhibition of temptations by goal-relevant objects serves as a mechanism of self-control, then it should be evident only among those who actually experience a self-control conflict (see Fishbach et al., 2003). That is, the effect of construal level on the inhibition of temptations by goal-relevant objects should be specific to those for whom dieting is a meaningful self-control conflict. Presumably, participants concerned with the goal will 
experience a self-control conflict when encountering temptations that may undermine the goal whereas those unconcerned with the goal are unlikely to experience a self-control conflict when encountering temptations that may undermine the goal. Thus, we predicted that those for whom dieting was an important goal, high-level construals would promote the inhibition of temptations by goal-relevant objects. However, we predicted that those for whom dieting was not an important goal, there would be little or no effect of construal level.

\section{Method}

\section{Participants}

Participants were 211 Ohio State University undergraduate students (123 women), who completed the study in exchange for course credit. Participants were randomly assigned to condition and tested in groups of 1 to 4 .

\section{Materials \& Procedure}

Construal-level manipulation. Participants first completed the construal-level manipulation exercise used in Study 2. That is, participants generated superordinate category labels versus subordinate exemplars for a series of 40 objects as an induction of high- versus low-level construals, respectively.

Lexical decision task. After the participants completed the construal-level manipulation exercise, they completed a lexical decision-based sequential priming task (LDT) on a computer to assess the inhibition of temptations by goal-relevant objects.

The LDT in Study 3 reverses the use of goal-relevant objects and temptations in the previous studies. Specifically, the goal-relevant objects were used as primes (instead of targets) and the temptations were used as targets (instead of primes). In all other 
respects this LDT is the same as the LDT used in Studies 1 and 2 (see Study 1 for the specific details).

Other measurements. All other procedures and materials were identical to that of the previous studies. As in the previous studies, the responses to the goal importance questions were averaged to obtain an index of goal importance $(\alpha=.88)$. As in the previous studies, none of the participants reported a relationship between the construallevel manipulation exercise and the LDT.

\section{Results and Discussion}

The inhibition of temptations by goal-relevant objects was measured using a facilitation score. Given the difficulty of interpreting latencies for errors, only correct responses were used in all of the analyses (Bargh et al., 1992; Fazio, 1990). The average error rate for participants in the LDT was $7.8 \%$. First, to control for excessive positive skew, response latencies were trimmed within $\pm 2.5 S D$ of each participants' cell mean. The facilitation score was calculated by subtracting the average response latencies in the critical trials (goal-relevant objects priming temptations) and the average response latencies in the comparison trials (neutral words priming temptations). The more positive the facilitation score, the less accessible the temptations.

Facilitation scores were regressed onto construal level and goal importance. Although not statistically significant, the direction on the effect of goal importance replicated earlier work by Fishbach et al. (2003), $B=.05, t(207)=0.66, p=.51$. That is, as the importance dieting increased, temptations became less accessible. More importantly, we obtained an interaction between construal level and goal importance, $B=$ $.12, t(207)=1.66, p=.10($ See Figure 3$)$. 


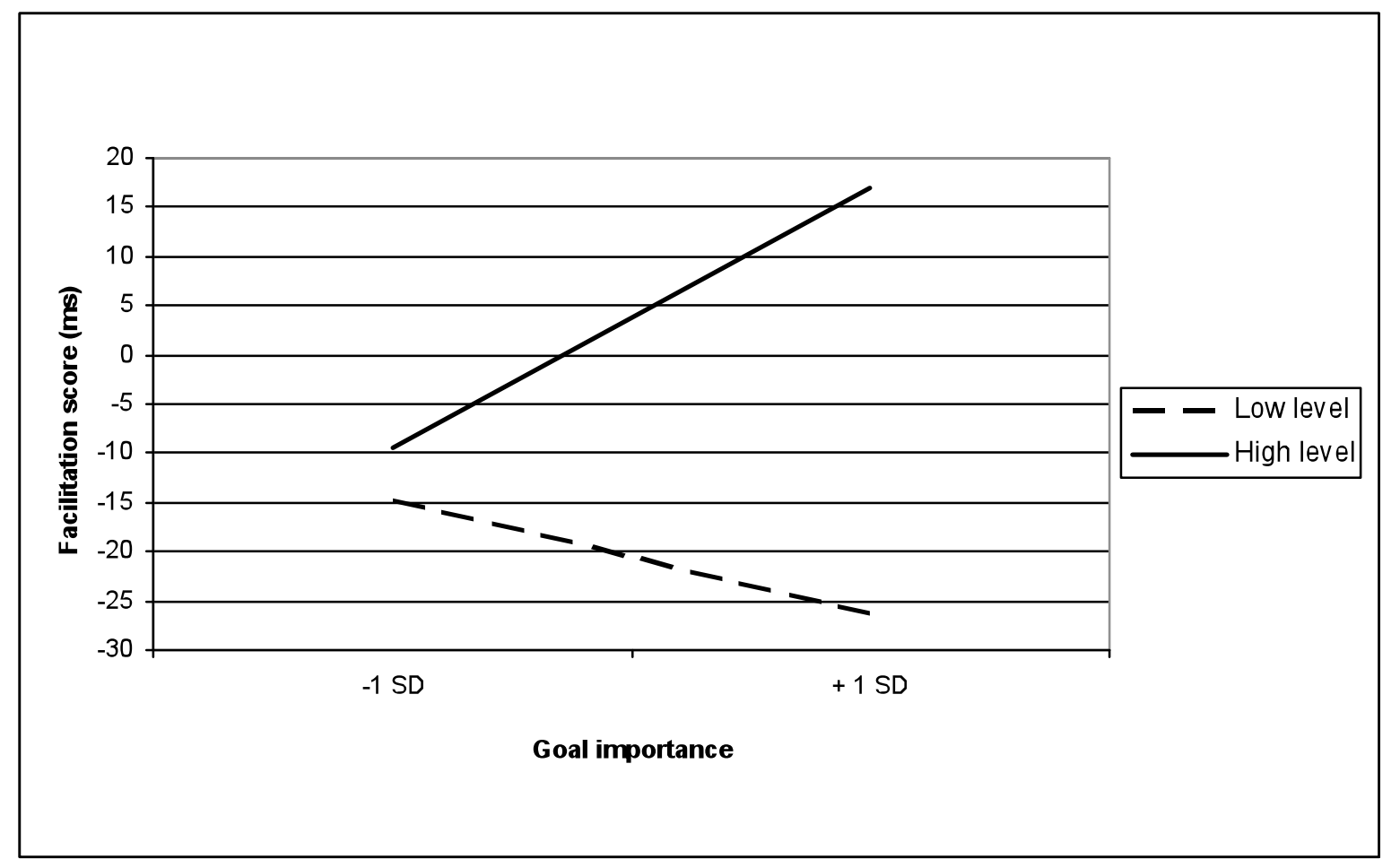

Figure 3. The inhibition of temptations by goal-relevant objects as a function of construal level and goal importance. The more positive the facilitation score, the less accessible the temptations. When the goal was important, defined as one standard deviation above the mean, high-level construals led to greater inhibition of temptations by goal-relevant objects than low-level construals.

For those whom dieting was important and thus represented a meaningful selfcontrol conflict, high-, rather than low-level construals inhibited thoughts of temptations by goal-relevant objects, $B=.26, t(207)=2.69, p<.01$. On the other hand, for those whom dieting was not important and thus did not represent a meaningful self-control conflict, construal levels did not affect the activation of temptations by goal-relevant objects, $B=.04, t(207)=0.34, p=.74$.

These analyses support three conclusions. First, that high-, rather than low-, level construals cause thoughts of temptations to be inhibited by goal-relevant objects. 
Second, that high-level construals cause greater inhibition of temptations by goal-relevant objects only for those in which there is a meaningful self-control conflict (i.e., those participants indicating that dieting was important). Third the findings demonstrate, when taken together with the other two studies, that levels of construal determine whether selfcontrol benefits from the asymmetric cognitive association between temptations and goals (Fishbach et al., 2003). When individuals are at the high-level, the asymmetric cognitive association between temptations and goals works, when they are at low-level, it does not. We would like to suggest that this data provides evidence for the idea that the automatic activation of goals by temptations and inhibition of temptations by goals are mechanisms by which high-level construals promote the weighting of global concerns over local concerns and thus promotes self-control.

The previous studies used goal-relevant objects as targets (Study 1 and 2) or primes (Study 3). While goal-relevant objects and goals are conceptually distinct (see above), in these studies and past studies (Fishbach et al., 2003, Study 2 and 3), goalrelevant objects were used as a proxy for goals. The next study was designed to test whether construal levels would influence the activation of temptations by goals if the goals themselves were used as primes, instead of the goal proxies (i.e., goal-relevant objects). Thus, Study 4 was designed to test whether construal levels would moderate the inhibition of temptations by the goals themselves (Fishbach et al., Study 4). 


\section{CHAPTER 5}

\section{STUDY 4}

Study 4 was designed to conceptually replicate the findings in Study 3. A key distinction in Study 4 is that the goals themselves (e.g., thin) are used to prime temptations instead of goal-relevant objects (e.g., salad); however, the procedures and analyses used in this study are similar to those in Study 3. Participants completed an exercise similar to the exercise used in Study 1 to procedurally prime high or low levels of construal. After the construal-level exercise, the carryover effects of the exercise were observed on a lexical decision task that was designed to assess the cognitive association between temptations and goals.

Conceptually speaking we make the same prediction. Namely, that the inhibition of temptations by goals would be moderated by levels of construal and goal importance. Using dieting as the focal self-control conflict, we measured the activation of temptation words by goal words versus non-goal words. We predicted the inhibition of temptations by goals would happen at the high-, rather than low-, level construal. However, since the inhibition of temptations by goals serves as a mechanism of self-control, we predicted that this inhibition would only occur for those who actually experience a self-control conflict. That is, the effect of construal levels on the inhibition of temptations by goals 
should be specific for those concerned with dieting. Those who are not concerned with dieting are unlikely to experience a self-control conflict and thus construal levels should have little effect. Thus, we predicted that among those for whom dieting was an important goal, high-level construals would promote the inhibition of temptations by goals. However, we predicted that among those for whom dieting was not an important goal, there would be little or no effect of construal level.

\section{Method}

\section{Participants}

Participants were 161 Ohio State University undergraduate students (84 women), who completed the study in exchange for course credit. Participants were randomly assigned to condition and tested in groups of 1 to 4 .

Materials \& Procedure

Construal-level manipulation. Participants first completed a construal-level manipulation exercise similar to the construal-level manipulation exercise used in Study 1. That is, participants were procedurally primed at high or low levels of construal by generating either superordinate ends to particular activities or subordinate means to particular activities. Specifically, half of the participants were procedurally primed at high-levels by considering why they engaged in certain actions whereas the other half of the participants were procedurally primed at low-levels by considering how they engaged in certain actions. Unlike Study 1 where the activities differed depending on the condition (high or low) the participant was assigned, the activities in Study 4 were the same in both conditions. The activities were improving and maintaining good grades and dressing well. 
Participants assigned to the high-level condition were presented with the questions "Why do I improve and maintain good grades?" and "Why do I dress well?" Conversely, low-level participants were presented with the questions "How do I improve and maintain good grades" and "How do I dress well?" Participants first generated responses to the questions regarding improving and maintaining good grades then finished the exercise by generating responses to the questions regarding dressing well (see Study 1 for the specifics of the manipulation).

Lexical decision task. After the participants completed the construal-level manipulation exercise, they completed a lexical decision-based sequential priming task (LDT) on a computer. The LDT was designed to measure the cognitive association between temptations by goals. As in the other studies, participants were presented with series of letter strings and asked to determine as quickly as possible whether the letter string was a word or nonword (for the specifics regarding prime and target presentation see Study 1). Participants completed a total of 56 trials, half of which presented word trials ( 28 trials). Of these latter trials, 14 trials presented goals that dieting may serve. In 7 of these trials (critical trials), the temptations were preceded by goals. An additional 7 of these trials (comparison-trials), the temptations preceded non-goal word primes. The specific prime-target pairings were determined by matching word frequency and word length (Anderson, 1983). As such, the specific prime-target pairings in the critical trials were: diet-cake, slim-chips, thin-sugar, fit-cream, skinny-dessert, slender-cookies, leanbeer. The specific prime-target pairings in the comparison trials were: knee-cake, downchips, sky-sugar, tie-cream, revised-dessert, troubled-cookies, roll-beer. The remaining 
20 trials were neutral trials and consisted of identifying neutral target words as words or nonwords after being exposed to neutral primes.

Measurement of goal importance. After the participants completed the LDT they were asked the extent dieting, being slim, thin, fit, skinny, slender and lean were important goals to them. Namely, participants were asked "Is dieting an important goal for you to accomplish?" and "To what extent is being an important goal for you?" Participants responded using a 7 -point Likert scale $(1=$ not at all, $7=$ extremely $)$. The seven items were averaged to obtain an index of goal importance $(\alpha=.90)$. Participants then provided demographic information (e.g., gender, age, year in school). Upon completion, a funneled debriefing was administered. None of the participants reported a relationship between the construal-level manipulation exercise and the LDT. Afterward, they were carefully debriefed and dismissed.

\section{Results and Discussion}

The inhibition of temptations by goals was measured using a facilitation score. Given the difficulty of interpreting latencies for errors, only correct responses were used in all of the analyses (Bargh et al., 1992; Fazio, 1990). The average error rate for the participants in the LDT was $6.4 \%$. First, to control for excessive positive skew, response latencies were trimmed within $\pm 2.5 S D$ of each participants' cell mean. The facilitation score was calculated by subtracting the average response latencies in the critical trials (goals priming temptations) and the average response latencies in the comparison trials (neutral words priming temptations). The more positive the facilitation score, the less accessible the temptations. 
Facilitation scores were regressed on construal level and goal importance. While not statistically significant, the effect of goal importance replicated earlier work by Fishbach et al. (2003), $B=.12, t(157)=1.55, p=.12$. That is, as goal importance increased, temptations become less accessible after being primed with goals. More importantly, we obtained a significant interaction between construal level and goal importance, $B=.16, t(157)=2.04, p=.04$ (See Figure 4).

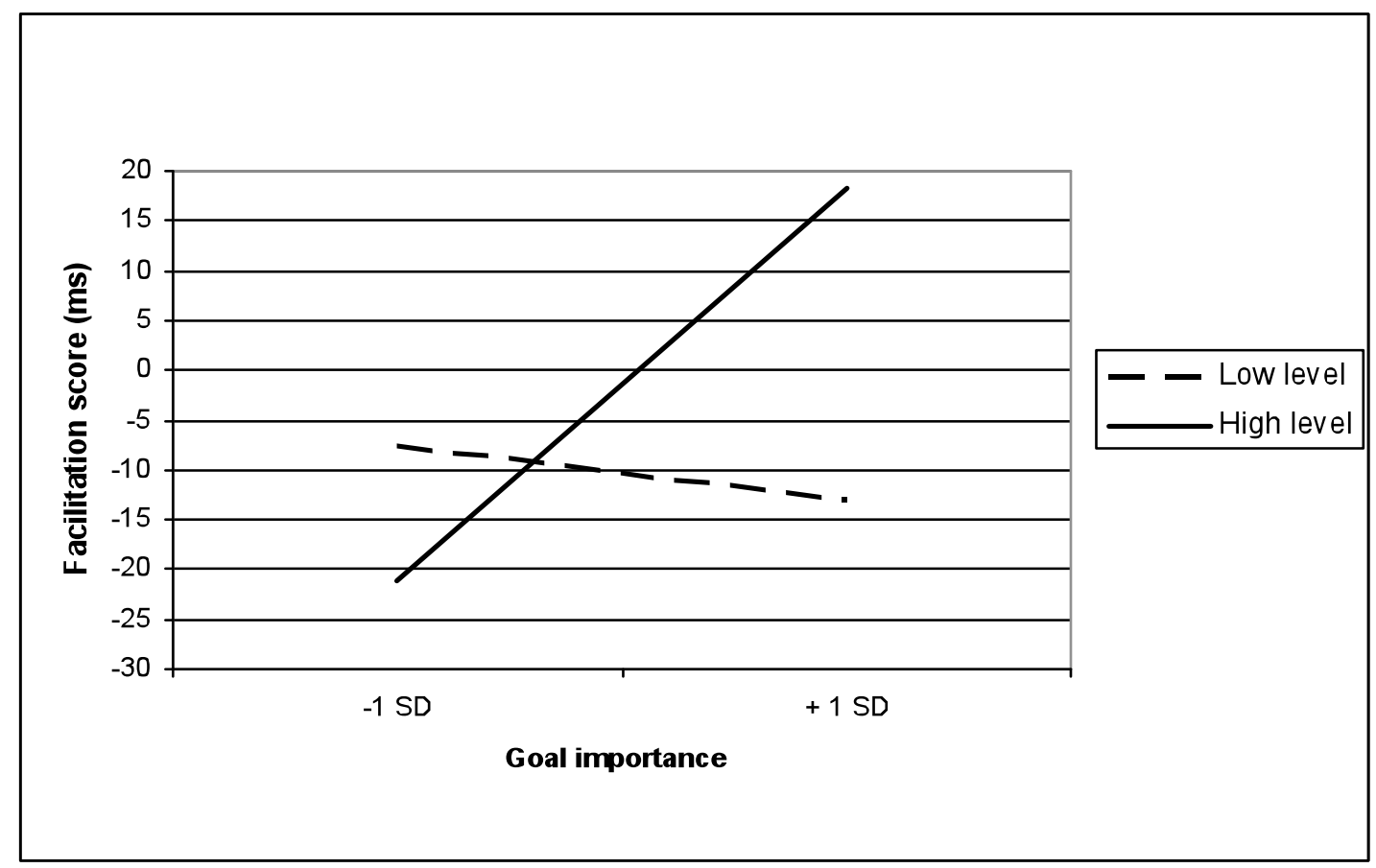

Figure 4. The inhibition of temptations by goals as a function of construal level and goal importance. The more positive the facilitation score, the less accessible the temptations. When the goal was important, defined as one standard deviation above the mean, highlevel construals led to greater inhibition of temptations by goals than low-level construals. 
For those whom the goal was important and thus represented a meaningful selfcontrol conflict, high-, rather than low- construals inhibited thoughts of temptations by goals, $B=.22, t(157)=2.02, p=.05$. On the other hand, for those whom the goal was not important and thus did not represent a meaningful self-control conflict, construal levels did not affect the activation of temptations by goals, $B=-.10, t(157)=-.87, p=$ .39 .

These analyses support four conclusions. First, that high-, rather than low-, level construals cause thoughts of temptations to be inhibited by goals. Second, that high-level construals cause greater inhibition of temptations by goals only for those who experience a self-control conflict (i.e., those participants indicating that dieting was an important goal). Third, when taken together with the other three studies, these findings suggest that when individuals are at the high-level, the asymmetric cognitive associations between temptations and goals operate successfully, when they are at the low-level, they do not. Fourth, we would like to argue that these patterns of data suggests that one of the mechanisms by which high-level construals promote the weighting of global concerns over local concerns is through the asymmetric activation patterns between temptations and goals. 


\section{CHAPTER 6}

\section{GENERAL DISCUSSION}

The studies reported here were designed to test the hypothesis that the activation of high levels of construal would lead to greater asymmetric activations between temptations and goals than low levels of construal. That is, the studies were designed to test whether high-level construals would promote the automatic activation of goals by temptations and the inhibition of temptations by goals more than low-level construals. Evidence in support of this would suggest that one of the mechanisms by which highlevel construals promote the weighting of global concerns (i.e. goals) over local concerns (temptations) is by promoting the asymmetric activation patterns between temptations and goals.

Study 1 and 2 provided support that high-level construals promote the activation of goals by temptations whereas Study 3 and Study 4 showed that high-level construals promote the inhibition of temptations by goals. In Study 1, participants who were procedurally primed with questions about why they engaged in actions (high-level) showed more automatic activation of goal-relevant objects by temptations than participants who were procedurally primed with questions about how they engaged in actions (low-level). Similarly, in Study 2, participants who were asked to create category 
labels for stimuli (high-level) exhibited more automatic activation of goal-relevant objects by temptations than participants who were asked to provide exemplars for the stimuli (low-level). Examining the inhibition of temptations by goal-relevant objects, Study 3 showed that participants who were asked to create category labels for stimuli (high-level) exhibited more inhibition of temptations by goal-relevant objects than participants who were asked to provide exemplars for stimuli (low-level). Using the goals themselves instead of their proxies (i.e., goal-relevant objects), Study 4 showed that participants who were procedurally primed with questions about why they engaged in actions (high-level) exhibited more inhibition of temptations by goals than participants who were procedurally primed with questions about how they engaged in actions (lowlevel). Using two different manipulations of construal level, high levels of construal were shown to lead to greater automatic activation of goal-relevant objects by temptations than low levels of construal. Similarly, using two different manipulations of construal level, high levels of construal were shown to lead to more inhibition of temptations by goal-relevant objects and goals than low levels of construal. The results of four experiments suggest that one of the mechanisms by which high-level construals weight global concerns (i.e., goals) over local concerns (i.e., temptations) is through the asymmetric activation patterns between temptations and goals.

The four studies in this work provide further support for a construal level approach to self-control (Fujita et al., 2006). In these studies, high-level construals were shown to enhance self-control by promoting the use of asymmetric activation patterns between temptations and goals, a cognitive measure of self-control (Fishbach et al., 2003). In doing so, this work illuminates one of the social-cognitive mechanisms by 
which high-level construals weight global concerns over local concerns and thus promote self-control (Fujita et al., 2006).

This work also extends a construal level approach to self-control because it shows that construal levels moderate an automatic process known to influence self-control (Fishbach et al. 2003). Previous research examining self-control from a construal level perspective showed that construal levels could influence self-control decisions but left open the question whether construals could operate on the automatic processes involved in self-control (Fujita et al., 2006). This work, to our knowledge, is the first to show that construal levels can influence self-control at the automatic level. The activation of goals by temptations is automatic in the sense that no conscious intent or effort was involved (Bargh, 1994). This work suggests the importance of subjective meaning in understanding self-control because mental construals influenced whether automatic selfcontrol processes were initiated.

Since levels of construal influenced whether automatic self-control processes were initiated, factors that systematically influence levels of construal may also affect automatic self-control processes. The factors that systematically influence levels of construal, and potentially self-control, are well documented. For example, research has shown that the global processing of visual information is more likely under positive moods than neutral moods (Gaspar \& Clore, 2002) suggesting that positive moods may increase self-control by activating high levels of construal (Gervey, Igou, \& Trope, in press). Research has also shown that possessing power, having control over another person's outcomes (e.g., Fiske \& Berdahl, 2007), leads to more abstract processing which suggests that power may increase self-control through the activation of high-level 
construals (Smith \& Trope, 2006). Additionally, psychological processes that activate high levels of construal like superordinate categorization (Study 2 and 3) or abstract reasoning may enhance self-control. On the other hand, psychological processes that lead to the activation of low levels of construal like focusing on the means or implementations of actions rather than why the actions where engaged in the first place (Study 1 and 4) may impair self-control.

Psychological distance is also likely to enhance or impair self-control through the activation of construal levels. CLT posits that psychological distance leads to the activation of high-level construals whereas psychological proximity leads to the activation of low-level construals (Liberman et al., 2007; Trope \& Liberman, 2003). Accordingly, psychological distance from a self-control conflict should lead to greater self-control through the activation of high-level construals whereas psychological proximity may impair self-control through the activation of low-level construals. There is empirical evidence to suggest that psychological distance enhances self-control (e.g., Bernartzi \& Thaler, 2004).

Individual differences in the tendency to use high- versus low-level construals may also influence automatic self-control processes. Research on action identification has shown that individuals who chronically identified their actions in abstract, high-level terms (high-level agents) reported being less impulsive than individuals who chronically identified their actions in concrete, low-level terms (low-level agents) (Vallacher \& Wegner, 1989). Research by Freitas, Salovey, \& Liberman (2001) provided evidence showing that high-level agents demonstrate more self-control when seeking self-relevant 
information than low-level agents. High-level agents may thus initiate automatic selfcontrol processes more than low-level agents.

Deliberate control of impulses is a feature that is common in many models of selfcontrol (e.g., Baumeister \& Heatherton, 1996; Metcalfe \& Mischel, 1999; Ainslie \& Haslam, 1992). However, these data, in addition to past work on self-regulation (Moskowitz, Gollwitzer, Wasel, \& Schaal, 1999; Fishbach et al, 2003; Shah et al., 2002) suggest that deliberative intent is not necessarily a requirement for self-control because automatic self-control processes can be implemented. At the same time, this also work enlightens research on automatic self-control processes. Theoretically, it has been posited that these automatic self-control processes are in place for those who are especially efficient at self-control and for those whom self-control is of high importance (Moskowitz et al., 1999; Fishbach et al., 2003; Shah et al., 2002; Fitzsimons \& Shah, in press). That is, the development of these processes results from being "good" at selfcontrol. However, these studies and past work examining self-control from a construal level perspective (Fujita et al., 2006) argues for a situational understanding of self-control since even "good" self-controllers can fail at self-control. In these studies, dieters failed to show the asymmetric activation patterns between temptations and goals, a cognitive system shown to promote self-control (Fishbach et al., 2003), when they were at low levels of construal. Similarly, work by Fujita et al. (2006, Study 2) showed that individuals displayed less physical endurance in a task to obtain ostensibly important feedback when they were at low levels of construal. The current work helps illustrate that the story of self-control is more dynamic than just individual perseverance in an 
environment saturated with temptations and shows how situational variables could affect self-control.

In addition to providing a dynamic account of self-control, a construal level perspective, may provide understanding when contradictory findings emerge. As mentioned before, Fishbach et al. (2003) showed evidence that goals are automatically activated by temptations. For example, using dieting as a focal self-control conflict, Fishbach et al. (2003, Study 4) found that temptation-related words like cake facilitated identification of goal words that dieting may serve like thin. On the other hand, Papies, Stroebe, and Aarts (2007) found that dieters, presented temptations, spontaneously thought of the hedonic aspects of the temptations (scrumptious, tasty), thoughts that would be inconsistent with the goal to diet. These findings seem to contradict each other. However, a construal level approach to self-control suggests a way at reconciliation. Specifically, a construal level approach suggests that participants were at high levels of construal in Fishbach et al. (2003), whereas participants were at low levels of construal in Papies et al. (2007). While we do not have any direct evidence in our studies that the dieters in the low-level condition activated hedonic thoughts toward temptations, it is clear that they were not thinking of their dieting goals (Study 1 and 2). Future research will determine whether this is actually the case. A construal level approach to selfcontrol thus has the potential to explain contradictory findings in the self-regulation literature in addition to generating new research.

This work also adds to the growing body of evidence suggesting for the conceptual distinction between high- versus low-level construals and non-effortful versus effortful processing (Smith \& Trope, 2006; Wakslak, Trope, Liberman, Alony, 2006; 
Fujita, Chaiken, Trope, \& Liberman, 2008). The distinction is meaningful. For example, work by Fujita et al. (2008) found that effortful processing is associated with both highand low-level construals with level of construal affecting what information was attended to. Exemplar-based information was preferentially attended to at low-level construals whereas category-based information was preferentially attended to at high-level construals (Fujita et al., 2008, Study 3). In this work, high-level construals were associated with more and less automaticity (facilitation of goals by temptations but inhibition of temptations and goals, respectively) suggesting that construals are indeed independent of processing mode.

In sum, this work speaks broadly to research on self-regulation and provides further evidence to support a construal level approach to self-control. Regarding the former, this work highlights the importance of meaning making in studying self-control processes since the mental construal of the self-control conflict was shown to influence self-control processes. Concerning the latter, the work provides evidence for one of the social-cognitive mechanisms by which high-level construals weight global concerns over local concerns. Specifically, through the use of the asymmetric activation patterns between temptations and goals, high-level construals help keep our global concerns accessible so that our thoughts and behaviors may be biased in favor self-control. The work also extends previous work on construal levels and self-control, since this work is the first to demonstrate the influence of construal levels on automatic self-control processes. 


\section{Conclusion}

The present work showed that construal levels moderated the asymmetric activation patterns between temptations and goals. Specifically, this work showed that high-level construals lead to greater activation of goals by temptations and greater inhibition of temptations by goals than low-level construals. This pattern of data suggests that one of the mechanisms by which high-level construals weight global concerns over local concerns is through the use of the asymmetric activation patterns between temptations and goals. Through these asymmetric activations, high-level construals ensure that our global concerns are at the forefront of our thoughts, and bias decisionmaking and behavior in favor of self-control. 


\section{Footnotes}

Footnote 1. Research has suggested (McCulloch, Aarts, Fujita, \& Bargh, 2008) that it is impossible to know from spreading activation paradigms whether response latencies reflect de-activation of nodes or weakened links between nodes --the effects of the former reflecting true inhibition (concept $\mathrm{A}$ is less accessible below its baseline activation) and effects of the latter from a weakened association between two concepts (concept A is still active, but the association between concept $\mathrm{A}$ and $\mathrm{B}$ is reduced). Using spreading activation paradigms, previous research on the functionality of reduced cognitive activation among competing goals, means, and temptations in goal-pursuit interprets slowed response latencies as inhibition not weakened associations (e.g., Fishbach et al., 2003; Shah, Friedman, \& Kruglanski, 2002). However, since it is not empirical possible to differentiate inhibition and weakened associations without a baseline, we take a more conservative interpretation and refer to inhibition as the weakened association between nodes rather than as inhibition of nodes themselves. 


\section{REFERENCES}

Aamodt, S., \& Wang, S. (2008). Tighten your belt, strengthen your mind. The New York Times. Retrieved May 21, 2008, from http://www.nytimes.com/2008/04/02/opinion/02aamodt.html?_r=1\&em\&ex=120 $\underline{7454400 \& \text { en }=0 \mathrm{ca} 7 \mathrm{a} 89030 \mathrm{aadb0d} \& \mathrm{ei}=5087 \% 0 \text { A\&oref }=\text { slogin }}$.

Anderson, J. R. (1983). The architecture of cognition. Cambridge, MA: Harvard University Press.

Ainslie, G. (1975). Specious reward: A behavioral theory of impulsiveness and impulse control. Psychological Bulletin, 82, 463-496.

Ainslie, G., \& Haslam, N. (1992). Hyperbolic discounting. In G. Loewenstein \& J. Elster (Eds.), Choice over time (pp. 57-92). New York: Russell Sage Foundation.

Anderson, M. C., \& Spellman, B. A. (1995). On the status of inhibitory mechanisms in cognition: Memory retrieval as a model case. Psychological Review, 102, 68-100.

Baumeister, R. F., Bratslavsky, E., Muraven, M., \& Tice, D. M. (1998). Ego depletion: Is the active self a limited resource? Journal of Personality and Social Psychology, 74, 1252-1265.

Baumeister, R. F., \& Heatherton, T. F. (1996). Self-regulation failure: An overview. Psychological Inquiry, 7, 1-15.

Baumeister, R. F., Schmeichel, B. J., \& Vohs, K. D. (2007). Self-regulation and the executive function. The self as controlling agent. In A.W. Kruglanski \& E.T. Higgins (Eds.), Social Psychology: A handbook of basic principles $\left(2^{\text {nd }}\right.$ Ed., pp. 516-539). New York: Guilford.

Bargh, J. A. (1994). The four horsemen of automaticity: Awareness, intention, efficiency, and control in social cognition. In R. S. Wyer, Jr. \& T. K. Srull (Eds.), Handbook of Social Cognition, (2 ${ }^{\text {nd }}$ Ed., pp. 1-40). Hillsdale, NJ: Lawrence Erlbaum Associates.

Bargh, J. A., Chaiken, S., Govender, R., \& Pratto, F. (1992). The generality of the automatic attitude activation effect. Journal of Personality and Social Psychology, 62, 893-912. 
Bargh, J. A., Chen, M., \& Burrows, L. (1996). Automaticity of social behavior. Journal of Personality and Social Psychology, 71, 230-244.

Benartzi, S., \& Thaler, R. H. (2004). Save more tomorrow: Using behavioral economics to increase employee saving. Journal of Political Economy, 112, 164-187.

Blair, I. V., \& Banaji, R. (1996). Automatic and controlled processes in stereotype Priming. Journal of Personality and Social Psychology, 70, 1142-1163.

Devine, P. G. (1989). Stereotypes and prejudice. Journal of Personality and Social Psychology, 56, 5-18.

Fazio, R. H. (1990). A practical guide to the use of response latencies in social psychological research. In C. Hendrick \& M.S. Clark (Eds.), Review of personality and social psychology (Vol. 11, pp. 74-97). Newbury Park, CA: Sage.

Fishbach, A., Friedman, R. S., \& Kruglanski, A. W. (2003). Leading us not unto temptation: Momentary allurements elicit overriding goal activation. Journal of Personality and Social Psychology, 84, 296-309.

Fishbach, A., \& Ferguson, M. (2007). The goal construct in social psychology. In A. W. Kruglanski \& E. T. Higgins (Eds.), Social Psychology: A handbook of basic principles $\left(2^{\text {nd }}\right.$ Ed., pp. 490-515). New York: Guilford.

Forster, J., Friedman, R. S., \& Liberman, N. (2004). Temporal construal effects on abstract and concrete thinking. Consequences for insight and creative cognition. Journal of Personality and Social Psychology, 87, 177-189.

Freitas, A. L., Salovey, P., \& Liberman, N. (2001). Abstract and concrete self-evaluative goals. Journal of Personality and Social Psychology, 80, 410-424.

Freitas, A. L., Gollwitzer, P., \& Trope, Y. (2004). The influence of abstract and concrete mindsets on anticipating and guiding others' self-regulatory efforts. Journal of Experimental Social Psychology, 40, 739-752.

Fujita, K., Trope, Y., Liberman, N., \& Levin-Sagi, M. (2006). Construal levels and selfcontrol. Journal of Personality and Social Psychology, 90, 351-367.

Fujita, K., Eyal, T., Chaiken, S., Trope, Y., \& Liberman, N. (2008). Influencing attitudes toward near and distant objects. Journal of Experimental Social Psychology, 44, $562-572$. 
Gollwitzer, P. M., \& Brandstatter, V. (1997). Implementation intentions and effective goal pursuit. Journal of Personality and Social Psychology, 73, 186-1999.

Green, L., Fristoe, N., \& Myerson, J. (2004). Temporal discounting and preference reversals in choice between delayed outcomes. Psychonomic Bulletin \& Review, $1,383-389$.

Gross, J. (Ed.) (2007). Handbook of emotion regulation. New York: Guilford Publications.

Kruglanski, A. W., Shah, J. Y., Fishbach, A., Friedman, R., Chun, W. Y., \& SleethKeppler, D. (2002). A theory of goal systems. In M. P. Zanna (Ed.), Advances in experimental social psychology, (Vol. 34, 331-378). San Diego, CA: Academic Press.

Liberman, N., Sagristano, M., \& Trope, Y. (2002). The effect of temporal distance on level of mental construal. Journal of Experimental Social Psychology, 38, 523534.

Liberman, N., Trope, Y., \& Stephan, E. (2007). Psychological distance. In A. W. Kruglanski \& E. T. Higgins (Eds.), Social psychology: Handbook of basic principles (Vol. 2, pp. 353-383). New York: Guilford Press.

Loewenstein, G. F. (1996). Out of control: Visceral influences on behavior. Organizational Behavior and Human Decision Processes, 65, 272-292.

Macrae, C. N., Hewstone, M., \& Griffiths, R. J. (1993). Processing load and memory for stereotype-based information. European Journal of Social Psychology, 23, 77-87.

Metcalfe, J., \& Mischel, W. (1999). A hot/cool system analysis of delay of gratification: Dynamics of willpower. Psychological Review, 106, 3-19.

McCulloch, K. C., Aarts, H., Fujita, K., \& Bargh, J. A. (2008). Inhibition in goal systems: A retrieval-induced forgetting account. Journal of Experimental Social Psychology, 44, 614-623.

Mischel, W., \& Baker, N. (1975). Cognitive appraisals and transformations in delay behavior. Journal of Personality and Social Psychology, 31, 254-261.

Mischel, W., Shoda, Y., \& Rodriguez, M. L. (1989, May 26). Delay of gratification in children. Science, 244, 933-938.

Moskowitz, G. B., Gollwitzer, P. M., Wasel, W., \& Schaal, B. (1999). Preconscious control of stereotype activation through chronic egalitarian goals. Journal of Personality and Social Psychology, 77, 167-184. 
Muraven, M., \& Baumeister, R. F. (2000). Self-regulation and depletion of limited resources: Does self-control resemble a muscle? Psychological Bulletin, 126, 247-259.

Muraven, M., Tice, D. M., \& Baumeister, R. F. (1998). Self-control as a limited resource: Regulatory depletion patterns. Journal of Personality and Social Psychology, 74, 774-789.

Neely, J. H. (1977). Semantic priming and retrieval from lexical memory: Roles of inhibitionless spreading activation and limited-capacity attention. Journal of Experimental Psychology: General, 106, 226-254.

Papies, E., Stroebe, W., \& Aarts, H. (2007). Pleasure in the mind: Restrained eating and spontaneous hedonic thoughts about food. Journal of Experimental Social Psychology, 43, 810-817.

Rachlin, H. (1995). Self-control: Beyond commitment. Behavior and Brain Sciences, $18,109-159$.

Shah, J. Y., Friedman, R., \& Kruglanski, A. W. (2002). Forgetting all else: On the antecedents and consequences of goal shielding. Journal of Personality and Social Psychology, 83, 1261-1280.

Smith, P. K., \& Trope, Y. (2006). You focus on the forest when you're in charge of the trees. Journal of Personality and Social Psychology, 90, 578-596.

Thaler, R. H. (1991). Quasi rational economics. New York: Russell Sage Foundation.

Trope, Y., \& Fishbach, A. (2000). Counteractive self-control in overcoming temptation. Journal of Personality and Social Psychology, 79, 493-506.

Trope, Y., \& Liberman, N. (2000). Time-dependent changes in preferences. Journal of Personality and Social Psychology, 79, 493-506.

Trope, Y., \& Liberman, N. (2003). Temporal construal. Psychological Review, 110, 403-421.

Trope, Y., \& Neter, E. (1994). Reconciling competing motives in self-evaluation. Journal of Personality and Social Psychology, 66, 646-657.

Vallacher, R. R., \& Wegner, D. M. (1987). What do people think they're doing?: Action identification and human behavior. Journal of Personality and Social Psychology, 57, 660-671. 
Wakslak, C. J., Trope, Y., Liberman, N., \& Alony, R. (2006). Seeing the forest when entry is unlikely. Journal of Experimental Psychology: General, 135, 641-653. 


\section{APPENDIX A Stimuli}

High-Level

Goal

Low-Level

Temptation

Neutral spinach, apple, broccoli, lettuce, yogurt, granola, wheat, peas, fruit, vegetable, radish, fiber, carrot, salad, celery, oranges, tofu, bran, tomato, grapes

beer, cookies, fries, sugar, nachos, dessert, cake, bacon, chips, pizza, hamburger, fastfood, candy, cheeseburger, sweets, soda, bar, cream, pancakes, buffet, butter, syrup, chocolate

time, man, people, good, world, house, home, thought, part, war, water, hand, young, father, present, face, white, church, power, family, interest, god, kind, door, name, death, body, field, car, money, free, air, boy, moment, street, board, love, wife, woman, mother, child, black, hard, strong, table, peace, red, alone, idea, cut, nature, fire, dark, space, spirit, hope, person, lost, heart, cold, river, building, natural, market, earth, fall, letter, square, blue, method, moral, color, trouble, army, chance, month, freedom, fear, beautiful, spring, hotel, truth, farm, plant, easy, respect, manner, progress, window, gun, horse, green, corner, quality, plane, wish, pretty, agreement, unit, doctor, glass, happy, army, pain, king, ship, youth, event, favor, knife, rock, dog, leader, advantage, detail, column, foot, rain, quick, dress, honor, broken, powerful, save, metal, coast, soft, imagine, victory, slow, circle, garden, lie, tree, taste, snow, safe, useful, sky, truck, hat, wagon, yellow, item, lake, grass, trust, gold, sick, engine, proud, tragedy, passage, milk, anger, plain, blind, cook, honest, engaged, humor, avenue, curious, liberty, terrible, angry, mold, snake, odd, dirt, iron, prison, weapon, smooth, pride, rough, queen, tool, finger, highway, talent, handsome, joy, mad, severe, clouds, palace, hurt, stomach, paint, innocent, bomb, dirty, shadow, satisfied, sad, waste, bench, patent, fish, vehicle, crime, bus, sugar, ocean, rejected, accident, violent, damage, alert, bride, gift, naked, swift, kids, wedding, troubled, bird, slave, virtue, impressed, secure, divorce, false, guilty, cow, modest, mighty, vigorous, delight, bullet, dawn, warmth, profit, victim, injury, excuse, reserved, chin, butter, gentle, cellar, unhappy, storm, legend, charm, lively, bath, cancer, promotion, lonely, devil, inspired, adult, honey, star, grateful, criminal, nervous, rigid, barrel, brave, controlling, habit, sentiment, flower, panic, fault, hide, sphere, autumn, triumph, joke, laughter, killer, jail, helpless, ugly, punishment, scared, startled, stiff, prairie, bold, melody, glory, intimate, luxury, lucky, poverty, hatred, crash, quarrel, clock, clothing, 
nude, wit, aroused, fever, flood, hay, cottage, crown, lamp 